\title{
The Problems of Modern Economic Development: The Fundamental Mechanics
}

Mikhail Semenovich Melnik

Leonid Feliksovich Orlov

Anastasia Viktorovna Bondarenko

Ekaterina Dmitrievna Melnik

Kristina Petrovna Grekova

Russian State Social University (RSSU), 129226, Moscow, Vilgelma Pika Street, 4, bld.1

\author{
Doi:10.5901/mjss.2015.v6n3p646
}

\section{Abstract}

Broad-scale economic crisis, which led to a number of serious attempts to understand the nature of ongoing social and economic processes and to analyze and evaluate the efficiency of the existing economic systems, is progressively subsiding. In current publications major attention is given to the solution of today's economic problems. Attempts are undertaken to reveal major trends of a new stage of economic development. Therefore identifying the basic patterns which led to the present-day economic crisis and which determine the pathway of the world economy development and provide a theoretical basis for economic forecasting and strategic planning of national economic development is a topical issue.

Keywords: Economic crisis, economic development, monetary policy, GDP growth rate, financial system, monetary reflation, intermediate-term cycle, long economic cycle, heavy market, major contraction, upward trend.

\section{Introduction}

The statistical data analysis indicates the general recovery trend is forming affected by the enhanced business activity of the developed countries' national economies. Surely during this period, the focus is on addressing the ongoing financial and economic policy challenges.

In the US the emphasis is put on monetary policy shaped by quantitative easing and aimed at concentrating significant amounts of investment money, which creates favorable conditions during the increasing business activity and the general trend of continuous and sustained dynamics in the world economy, aimed at providing fast and steady economic growth. During the second half of 2013, the US economy was developing at the fastest pace in a decade. In the $3^{\text {rd }}$ quarter the economy was growing at a $4 \%$ and in the $4^{\text {th }}$ quarter - at a $3.2 \%$ rate. Although the average growth rate for 2013 was 1.9\%, Chief Financial Economist at the New York's Bank of Tokyo-Mitsubishi UFJ Chris Rupkey stated: "The economy was firing on almost all cylinders as 2013 came to a close. For today, the sun is out and shining" (top.rbc.ru). Unstable but positive growth trends in the United States are observed in 2014 as well. In the $1^{\text {st }}$ quarter the economy showed only $0.1 \%$ growth, while in the second quarter it reached $4 \%$ which was significantly higher than the experts' forecasts. In general, according to the Bloomberg consensus forecast, this year American GDP is to increase by $3 \%$. This fact, along with the circumstances discussed below, indicates the potential strengthening of the US economy in the decades to come.

Canada goes through a similar stage of a gradual recovery still experiencing however the negative impacts of global trends. In this context Canadian territories' development budget totaled record-breaking 59 billion CAD. Closer attention is paid to financial incentives of innovational technology sectors. In 2012 and 2013 Canada's GDP growth equaled $1.7 \%$. In the $1^{\text {st }}$ quarter of 2014 it was $1.2 \%$, in the $2^{\text {nd }}$ quarter $-3.1 \%$, indicating the economy's slow but steady recovery from the global financial and economic crisis (afn.by).

Despite Japan's economy did not demonstrate higher rates of economic growth many analysts were predicting, its growth rate arrived at 1.4\% in 2012 and 1.5\% in 2013 (top.rbc.ru).

UK GDP growth in 2013 comprised 3.1\% which surpassed the 2008 level. Five largest economies of the monetary union: Germany, France, Italy, Spain and the Netherlands demonstrate positive yet very unstable dynamics, which in 
many ways still gravitate to stagnation. Eurozone countries lay their hopes mainly on monetary economic growth stimuli. At the same time, the opposite trends emerged in the most dynamically developing economies: Brazil, Russia, India and China, which gradually began to lose their leading positions in terms of economic growth. China's economy growth rates are slowing down: from 10.4\% in 2010 to 7.7\% in 2013, planned growth rate for 2014 is 7.5\% (Mikhaylov S, Lisovskaya V., 2014). In India, GDP growth decreased from $8.9 \%$ in 2010 to 4.7\% in 2013. The same rate is projected for 2014 (ved.gov.ru). In Brazil annual GDP growth by 7.5\% in 2010 was followed by a decrease to 1\% rate in 2012 and $2.5 \%$ in 2013. 1\% growth is planned for 2014 (bbc.com). The development of Russian economy also considerably slowed down: from 4\% in 2010 to 1.3\% in 2013. EBRD predicts zero growth rate in 2014 (Denisov A., 2014).

Observed economic slowdown trends in the developing countries showing a decline in efficiency of traditional economic growth drivers are the adjustment triggers in the wake of a new stage of the world economy development (Melnik M., Tikhomirova N., 2012).

\section{Method}

\subsection{Laws governing the falling phase of the III large economic cycle.}

Taking into account the ongoing debate the nature and the sources of the Great Recession as well as the need to forecast trends in global economic development, we offer our look at the issue. As opposed to the existing concepts of the subjective preconditions of the Great Recession (vedomosti.ru), our take is based on theoretical approaches to the economic cycles by N. Kondratiev (Kondratyev N.D., 2002, 379 s.), J. Schumpeter (Shumpeter Y., 2007), L. von Mises (Mizes L., 2000) and other researchers of this challenging economic problem (Yokhansson, F., 2008.).

Our calculations are based on the assumptions of $\mathrm{N}$. Kondratiev that the turning point of the third long economic cycle is determined by the crisis of 1920-1921. J.M. Keynes recognizes the crisis to a great extent shaped the Great Depression (Keynes, J.M. 1978). Another crisis that followed in 1929-1933 indicates the end of the first intermediate cycle of the downward wave with the average duration of 10-12 years. This cycle is marked by the economic recovery in the United States, thus mass goods production based on the assembly lines was launched. That provided an unprecedented growth in labor productivity and thus a 2.8 times increase in national income by 1927 as compared to the 1913 level.

Similar recovery processes with varying increase of production and different price indexes were taking place in Europe and Canada. But between 1929 and 1933 a decrease in industrial production started to appear.

The beginning of the Great Depression is linked with the economic crisis of 1929-1933, when the unprecedented stock panic began on October 24, 1929 followed by the stock market crash, what coincides with the end of the first intermediate-term cycle of the falling phase of a K-wave.

Such far-reaching implications of the crisis were caused by the enhancement of the negative effect of the crisis amidst the general trend of the rising phase of a K-wave: "Indeed if we consider intermediate-term cycles that fall on a falling phase of a large wave, it is obvious that all the upward trends of elements involved in intermediate-term cycles will be weakened, and all the downward trends will intensify due to the downward nature of the K-wave phase" (Kondratiev, N. 2002).

Next wave's bottom generates in 1938-1939. In 1938 world's leading countries already demonstrated a decrease in industrial production. Hence the boundaries of the second intermediate-term cycle should be recognized as from 19291933 to 1938-1939. It can be assumed that the reduction of the second intermediate-term cycle is caused by the economies' failing to form upward trends against the backdrop of the overall falling phase.

The period of 1938-1945 indicates the growth of the US GDP by 65 percentage points. Meanwhile in Europe under the influence of warfare it reduced by $23 \%$. The figure for Japan was even lower. Another decline in production is observed in the United States in 1948-1949, for the first time since the end of World War II the decline affects more than $80 \%$ of economic sectors. Thus the boundaries of the $3^{\text {rd }}$ intermediate-term cycle of the $3^{\text {rd }} \mathrm{K}$-wave can be dated as 1938 1939 - 1948-1949, which makes the duration of its falling phase 28-29 years and points to the beginning of a rising phase in 1950.

\subsection{Laws governing the formation of large IV of the economic cycle.}

The economic recovery of the most war-torn countries was based on the significant volumes of imports from the United States including provisions for food, fuel, clothing, industrial equipment, raw materials, agricultural machinery, industrial goods, spare parts, etc., which influences the way those countries were involved in the shaping of the world's intermediate-term cycles. Until 1950 France's economy was growing fast surpassing the other European economies. 
Germany demonstrated high rates of industrial production. By 1950 its industrial output amounted to $113.7 \%$ of the 1936 level. UK was facing significant difficulties in stimulating economic growth which resulted in significantly lower growth rates. Japan was developing very rapidly and surpassed the European states in terms of GNP and industrial production.

However in 1957-1958, the economic crisis swept the countries much less affected by the devastating effects of World War II.

Specific for that crisis was the near absence of depression and recovery phases. The recession was followed by most considerable, widespread and long period of growth. This led to the conclusion made by G. Habeler (Haberler, G. 2007), according to whom, deep and long-lasting depressions are the thing of the past, which in our opinion is unreasonable as the similar phenomena of decline in production quickly followed by the rise was observed in crises that took place in the XVIII and XIX century.

Consequently, the $1^{\text {st }}$ intermediate-term cycle of the $4^{\text {th }}$ K-wave can be dated 1949-1950 - 1957-1958.

However World War II and the features of post-war reconstruction of national economies have led to mistiming of the intermediate-term cycles in the leading economies, changes in their behavior and their influence on the reproduction process.

But gradually the synchrony restored and was completed by the time of the 1973 crisis.

This crisis resembled the crisis of 1929-1933 marking a significant drop in industrial production and rate of securities. But in terms of duration and economic and social impact, they are not comparable. That's why the second intermediate-term cycle's timeframe is from 1957-58 to 1973.

The next intermediate cycle completing the rising phase of the $4^{\text {th }} \mathrm{K}$-wave is characterized by the fact that cost defining structure imbalances developed by 1973 were not overcome before 1980-s. The economic crisis, which began in 1979 and unfolded in 1980, was intensified by inflation, which led to an unprecedented rise of private banks' interest rates and stagnation of the US economy. By the spring of $198226 \%$ of production capacities were idle. That crisis was a turning point of the $4^{\text {th }} \mathrm{K}$-wave and the beginning of its falling phase.

The first intermediate-term cycle of the falling phase of the $4^{\text {th }} \mathrm{K}$-wave in the late $80 \mathrm{~s}$ - early $90 \mathrm{~s}$ was marked in the US by the Black Monday of 1987 and its negative consequences. This period is characterized by the deepest economic recession since the beginning of the 80s. It lasted until 1993.

The second intermediate-term cycle is defined by the fact that by 2001, the crisis was clearly visible in almost all sectors of the US economy - from high tech to agriculture. Investments and import-export activity have reduced, stock jobbing - intensified. Similar signs of a crisis were common in Japan and European countries during that period.

The third and final intermediate-term cycle of a falling phase of a K-wave is characterized by the economic crisis of 2007, which due to its relevance is subject to thorough examination and description.

\subsection{General and specific in the economic cycle.}

However the externals of the economic crises (a significant increase in money supply and its equivalents, mass stock market speculations) at first sight is seen as their cause.

The cause of the current global economic crisis has been described in a similar way - as a collapse of the US mortgage system which triggered a panic on the stock exchange with the expected results. And there is cautious optimism that the actions that prevented the collapse of the national banking system and a catastrophic decrease in industrial production will normalize the situation and bring economic recovery.

However, the logic under economic development leaves no room for such illusions. Similar phenomena prefaced lots of economic crises before 2007.

Therefore the following intermediate-term cycles and their duration can be distinguished based on their lower turning points and their correlation with the K-waves (Table 1).

Table 1. K-waves' and intermediate-term cycles' duration (XX - beginning of XXI century)

\begin{tabular}{|l|c|c|c|}
\hline Cycles & Beginning & End & Duration \\
\hline Falling phase of the 3rd K-wave & 1920 & 1949 & 29 years \\
\hline $1^{\text {st intermediate-term cycle }}$ & 1920 & $1929-1933$ & 11 years \\
\hline $2^{\text {nd }}$ intermediate-term cycle & $1929-1933$ & $1938-1939$ & 7 years \\
\hline $3^{\text {rd }}$ intermediate-term cycle & $1938-1939$ & 1949 & 10 years \\
\hline Rising phase of the $4^{\text {th }}$ K-wave & 1949 & 1980 & 30 years \\
\hline $1^{\text {st intermediate-term cycle }}$ & 1949 & $1957-1958$ & 8 years \\
\hline
\end{tabular}




\begin{tabular}{|l|c|c|c|}
\hline $2^{\text {nd }}$ intermediate-term cycle & $1957-1958$ & $1968-1969$ & 10 years \\
\hline $3^{\text {rd }}$ intermediate-term cycle & 1969 & $1979-1980$ & 11 years \\
\hline Falling phase of the $4^{\text {th }}$ K-wave & 1980 & till present & $\approx 29$ years \\
\hline $1^{\text {st }}$ intermediate-term cycle & 1980 & $1990-1991$ & 10 years \\
\hline $2^{\text {nd }}$ intermediate-term cycle & 1991 & $2001-2002$ & 10 years \\
\hline $3^{\text {rd }}$ intermediate-term cycle & 2002 & till present & 11 years \\
\hline Total duration of the $4^{\text {th }}$ K-wave & 1949 & till present & $\approx 60$ years \\
\hline
\end{tabular}

Source: author's calculations

The boundary of the $3^{\text {rd }} \mathrm{K}$-wave is determined by the first post-war crisis in the US economy. It is followed by a recovery period interrupted by the 1957 crisis. In Western Europe the long post-war growth period was punctuated by the occasional minor declines in production. Major trends of the falling phase of the $3^{\text {rd }}$ long wave and the $4^{\text {th }}$ long wave in general are reflected in the diagram of the US money multiplier changes by G. Rubino as well as in the diagram of the Kwaves by I. Gordon.

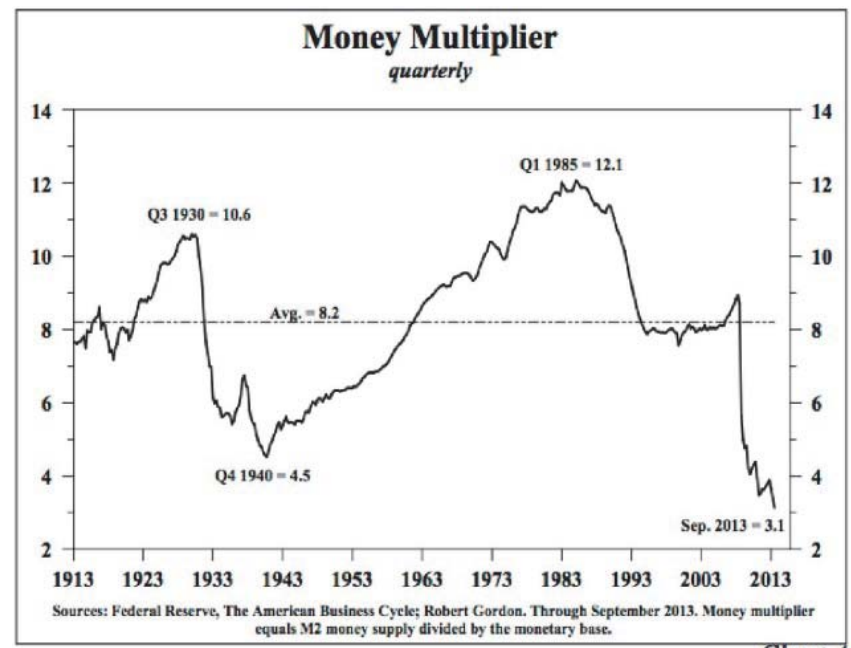

Diagram 1. The US money multiplier evolution

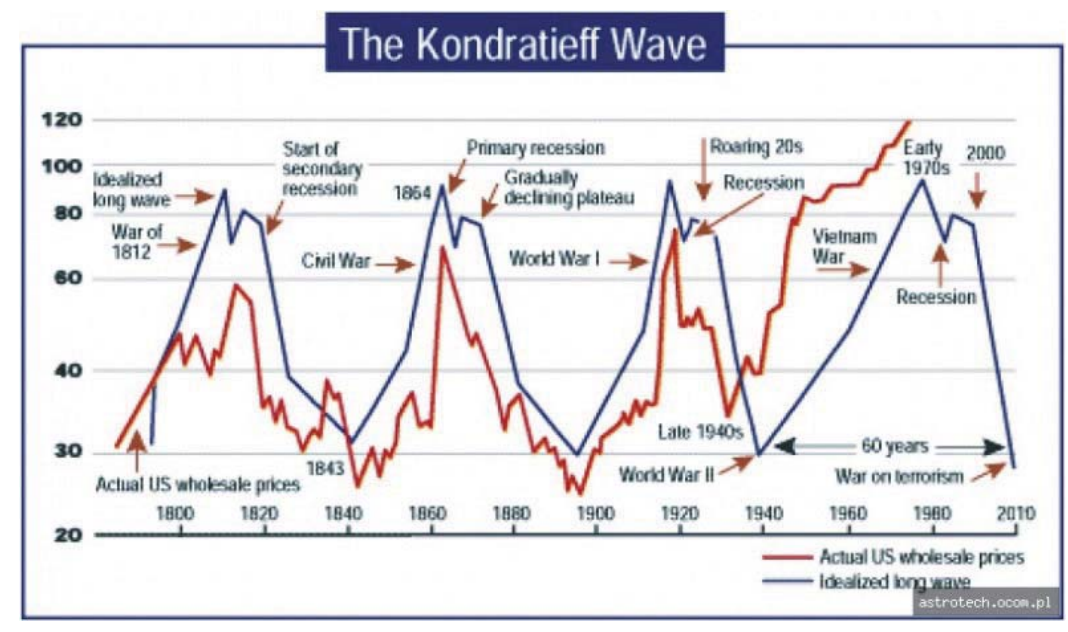

Diagram 2. I. Gordon's K-wave diagram

Average duration of the intermediate cycles of the $4^{\text {th }} \mathrm{K}$-wave rising phase equaled as follows: $1^{\text {st }}$ cycle -8 years, $2^{\text {nd }}$ cycle -11 years, $3^{\text {rd }}$ cycle -10 years. The total timeline of the falling phase was 30 years. Specific feature of the $3^{\text {rd }}$ intermediate cycle was the unsolved problems of the $2^{\text {nd }}$ cycle, due to which the 1973 crisis interrupted the shaping of a 
new cycle. By that time the objective economic preconditions for restoring the synchrony of the leading economies' cycles have formed in Europe and Japan that means the necessary prerequisites for the crisis have matured in their economies.

One of the other aspects of the post-war intermediate-term cycles is the reduced threshold of the economic indicators' decrease leading to a reduction in direct costs as a result of the crises, but in this regard and recovery phases have become longer.

Depressions have become rare. They became less typical for intermediate-term cycles and more correlated with the K-waves' tipping points. But a similar trend emerged in the XIX century and was noted by M. Tugan-Baranovsky (Tugan-Baranovsky, M.I. 1923).

But the most critical values for accessing economic trends in developed countries are capacity utilization and per capita GDP growth rate.

There was a sustained trend of reduction of capacity utilization. In the United States alone it comprised $75.6 \%$, including $73.2 \%$ in manufacturing and up to $62.1 \%$ in high-tech industries.

This trend was confirmed by a significant reduction of the real GDP per capita growth rate. Compared to 1980 level, in 2001 it equaled $78.9 \%$ in the US, $66.6 \%$ in the EU, 32.2\% in Japan. That's why this period of long recession and stagnation of the Japanese economy is often called the Great Recession.

\section{Result}

On that premise it can be argued that the recovery of the major world economies indicates the completion of the $4^{\text {th }} \mathrm{K}$ wave and the beginning of the first rising intermediate cycle of the $5^{\text {th }} \mathrm{K}$-wave which is supposed to end in 2039-2044. In this connection the US economy will again play the leading part which currently has several components. We will only mention two of the most important. Firstly, it has a significant technological advance and favorable conditions to use that advantage to form a rising phase of a K-wave. Therefore, an important feature of the new technologies is the need for large fixed investments with long life period which leads to uncertainty of future costs and prices, as well as the numerous organizational problems. Second factor is the mobility of social institutions that evolve under the influence of objective economic and structural changes brought by a rising phase of a new long wave.

Consequently, on the rising phase there occur certain tectonic shifts in the restructurization and cross-sectoral migration of employees. It is these significant changes in the structure of society that cause social disruptions. Economic, political and social institutions must prepare for these shocks in advance and acquire the appropriate flexibility, the ability to perceive the influence of radical structural economic reforms. To this end, even at present the most important function of the state should be the forecasting of upcoming changes in social institutions, deliberate preparation of the establishment and public opinion for the upcoming major changes in society, with a preliminary study of the relevant legislative and regulatory base to prevent aggravation of social contradictions.

\section{Discussion}

\subsection{Unsubstantiated claims about reducing the duration of high cycles.}

Thus given the dynamics and duration of the intermediate-term cycles there are no sufficient grounds to state that due to the information revolution and its impact on economic reproduction long K-waves have reduced to 45-50 years, as some Russian economists point out. If such changes actually took place this would have an effect on the duration of the intermediate-term cycles. But the dynamics of their reduction and increase in time during the falling phases of the $3^{\text {rd }}$ and the $4^{\text {th }} \mathrm{K}$-waves correlate with those of preceding K-waves.

Popularity of the views according to which scientific and technological progress is accelerating and the new technologies' lead time is constantly reducing is criticized even by G. Mensch, who is thought to give theoretical grounds to such thinking. Based on empirical data G. Mensh notes that even if such phenomena exist, those are improving innovations (Mensch, G. , 1979). Reduction of the lead time of a new basis technology occurs only within certain periods and does not affect the overall duration of the K-waves. Early basic innovations of the next long wave are implemented very slowly and painfully. Very few investors venture upon this step that involves a radical shift of a focus area, the necessity to establish new production and sales channels. It is also difficult to determine how the market will react to the innovation. Thus the lead time for technological innovations decreases only with favorable technological conditions. This is explained by a decrease of uncertainty and investment risks. The more investors involved - the greater the amount of investments which in turn attracts even more money.

However the cyclic nature of economic development stays in place. That's why the assessment of the current 
period of social production by the experts of the Bank of England can be considered as objective. According to the experts the global economic crisis of 2007 shows signs of the second Great Depression and in the materials of the World Bank, this crisis is dubbed the Great Recession.

\subsection{Exaggeration of the role of monetary factors in the Great Depression and the Great Recession.}

The Great Recession as well as the Great Depression developed during the falling phases of K-waves, during the $2^{\text {nd }}$ and the $3^{\text {rd }}$ intermediate-term cycles respectively. The lack of a common understanding of what caused the Great Depression was largely due to the fact that only the economic events that lay on the surface were subject to analysis. Intrinsically it was the global economic crisis which escalated in the late 20s - early 30s. This is shown by the synchrony of economic events. The US economy's rapid growth in the beginning of the 1920s gave way to a decline and an increasing downward trend. This is evident from the decline in production during 1924-1927 and a drop in investment in fixed production assets, a steady decline in car sales (a major durable merchandise) and decline in construction since 1926. It was becoming more obvious that a stable cyclical trend of worsening of business conditions was forming. However then and now most researchers overlook those obvious evidence of change in substantial characteristics of the economic development. The emphasis was placed on the analysis of individual monetary factors: lack of money supply in conjunction with overproduction provoked a deflation, which led to drop in commodity prices and the bankruptcy of a large part of their producers; a significant increase in speculative transactions which significantly increased the amount of fictitious capital caused financial bubbles creating an appearance of substantial excess of the money supply over demand; hidden inflation caused by violations of the gold standard which led to the increase in money supply by 62\%; budget deficit growth; rise in the accounts payable used for speculation on the stock exchange; overflow of money substitutes when the money supply growth had stopped. Besides monetary factors some other contributed to the depression: the law initiated by the senators Willis C. Hawley and Reed Smoot (Smoot-Hawley Tariff Act) that raised US tariffs to record levels which led to imports reducing by several times as well as the reduction in consumer demand; overproduction; large population growth rate; inadequate response of the stock exchange which created the illusion of growth amidst the cyclical economic decline; two contradictory trends: the drop in labor productivity and the growth of the money supply; unjustified increase in demand for securities, real estate influenced by the illusion of the upcoming prosperity, etc. But even if we try to logically link together the abovementioned set of factors, we will not find the causal mechanism of the economic crisis, that led to a long depression of the American and the world economy.

If we analyze the publications dedicated to the research into the causes of the current global economic crisis, we will largely see the same set of monetary factors interpreted as its reason. The negative role of the substantial increase of other countries' investment in the US securities; the accumulation of foreign exchange reserves by developing countries as well as the accumulation of sovereign oil funds; Federal Reserve's low interest rate policy, etc. are seen as the specific features of the crisis. Consequently, the crisis itself was originally defined as the global financial crisis with indisputably financial origins which allegedly follows from the sequence of unfolding events. At the same time it is repeatedly stated that the trigger of the current crisis was the set of contradictions in the US mortgage market.

Only some time later due to the nature of its escalation and drawn analogies with the Great Depression it was named the second Great Depression or the Great Recession.

In fact we see the same patterns that have been observed even in studies of XX century economic cycles. In particular in the studies of M. Tugan-Baranovsky (Tugan-Baranovsky, M.I. 1923) who pointed out that each economic crisis is preceded by a financial crisis provoked by the large-scale speculative operations on the stock market. Therefore we consider the current crisis as a manifestation of a general cyclical pattern of economic dynamics.

\section{Conclusion}

Brief overview of the major world economy centers suggests that the main negative effects of the Great Recession are barely being overcome and that the world economy generates the recovery phase of the economic cycle.

A substantial controversy arising in the society when implementing fundamentally new technologies over three next decades will be the need for significant organizational changes in the economic and political spheres and, therefore, improved regulatory role of the government. This is especially important because the forthcoming increase in labor productivity will be based on mass production automation, which entails a relative reduction of jobs in the production sphere and an increase in employment in the non-manufacturing sector. Consequently national economies and the global economy as a whole, are expecting large-scale structural changes, which are fraught with social upheavals, according to the patterns indicated by N. Kondratiev. He notes that the rising phases of the long waves are morey likely to cause major 
social upheavals and revolutions than the falling phases. He admits that the social upheavals are the result of the rapid growth period of the new forces in the economy.

Therefore, it is of utter importance to implement system solutions backed by the countries' financial, economic, scientific and technical potential, which will significantly enhance the role of the Russian economy at the world economy's recovery stage.

\section{References}

Brazilian central bank frees up \$13bn to boost economy (25 July 2014) http://www.bbc.com/news/world-latin-america-28490310 Canada's GDP grew in the 2nd quarter by 3.1\% (29 October 2014) http://afn.by/news/i/198493

Denisov A. EBRD downgraded the outlook on the dynamics of Russia's GDP in 2015 (27 September 2014) http://ria.ru/economy/20140918/1024557316.html

Haberler, G. (2007). Prosperity and Depression: A theoretical analysis of cyclical movements. Chelyabinsk: Socium.

Japan's economic growth fell short of expectations of analysts (6 October 2014) http://top.rbc.ru/economics/10/03/2014/910090.shtml

Johansson, F. (2008). The Medici Effect: What Elephants and Epidemics Can Teach Us About Innovation. Moscow: Williams.

John Rubino The Long Wave Versus the Printing Press: Central Banks Go All-In (29 September 2014) http://dollarcollapse.com/longwave/the-long-wave-versus-the-printing-press-central-banks-go-all-in/

Keynes, J.M. (1978). The General Theory of Employment, Interest and Money. Moscow: Progress.

Kondratiev, N.D (2002). The Major Cycles of the Conjuncture and the Theory of Forecasting. Moscow: Economics.

Kornai, J. (2002). The System Paradigm. Voprosy Economiki, 4, 6-9.

Melnik, M.S. (2013). The Evolutionary Nature of the Economic Cycles. Human Capital, 11.

Melnik, M.S., Tikhomirova, N.V. (2012). The Development of the Forecasting and Indicative Planning System Based on the Dynamics of the Economic Cycles. Economics, Statistics and Informatics, 1.

Mensch, G. (1979). Statement in Technology: Innovations Overcome the Depression. Cambridge.

Mikhailov S., Lisovska V. Chinese stability for Russia (6 October 2014) http://www.gazeta.ru/business/2014/07/16/6116325.shtml

Rario economica: The Great Recession: New Ideas (6 October 2014) http://www.vedomosti.ru/newspaper/article/254977 Ivelikaya_recessiya_novye_idei

Review of the economy in 2014 (6 October 2014) http://www.ved.gov.ru/exportcountries/in/about_in/eco_in/

Schumpeter, J. (2007). The Theory of Economic Development. Moscow: Eksmo.

Tugan-Baranovsky, M.I. (1923). Periodic industrial crises: History of British crises. The general theory of crises. Smolensk: Book publishing cooperative at Smolgubkom.

Von Mises, L. (2000). Human Action: A Treatise on Economics. Moscow: Economics.

Yakov G. Russian sour, sweet in the United States: economic growth went to the West (27 September 2014) http://top.rbc.ru/economics/21/02/2014/906394.shtml 
